\title{
CAPÍTULO VII \\ Acciones afirmativas de las mujeres en la construcción de paz desde nuevos territorios
}

\author{
Emma Doris López Rodríguez ${ }^{1}$
}

\footnotetext{
1 Abogada, Trabajadora Social y aspirante a Doctora en Ciencia Política. Dirigente de la Red de Mujeres contra la violencia. Docente Investigadora de la Universidad Simón Bolívar. Miembro del grupo Género Familia y Sociedad.

elopez16@unisimonbolivar.edu.co
} 


\title{
RESUMEN
}

Dentro de las esferas sociales, sensibilizar, recrear el espacio en medio de las diferentes manifestaciones de violencias y presentar este artículo en momentos de crisis, genera esperanzas para continuar la reconstrucción de tejido social desde este caminar, que como activista de derechos humanos y su defensora por más de veinte años, es luchar por encontrar los puntos convergentes, concertando desde las diferencias para lograr con hechos de paz, la Colombia que merecemos los ciudadanos. En atención a lo descrito, es importante desde ese caminar individual y del caminar colectivo, hacer un pare y que cada ser humano, cada ciudadano se percate de ese accionar. Es allí donde se desprende la importancia de la comprensión de la existencia de diferentes colores, sabores, olores, dolores, alegrías, certezas y esperanzas; en la que, tanto en ese colectivo como el individual, muchas personas desde la cotidianidad hacen aportes a la construcción de un nuevo país, a través de una visión integral cohesionadora del individuo, la familia y la comunidad en los ámbitos políticos, jurídicos, psicosociales y territoriales, con enfoque de género, étnico y orientación sexual.

Palabras clave: Violencia de género, Derechos humanos, Construcción de paz, Enfoque de género, Principio de igualdad, Acciones públicas.

\begin{abstract}
Within social spheres, sensitizing, recreating space in the midst of different manifestations of violence and presenting this article in moments of crisis, generates hopes to continue the reconstruction of social fabric from this walk that as a human rights activist and defender of them For more than twenty years, is to strive to find the converging points, agreeing from the differences to achieve with peace, the Colombia that we deserve the citizens. In the light of what has been described, it is important from that individual walk and the collective walk, to make a stop and that each human being, every citizen is aware of that action. It is there that the importance of the understanding of the existence of different colors, tastes, smells, pains, joys, certainties and hopes is revealed; In which both individuals and individuals, many people from the daily, contribute to the construction of a new country, through a comprehensive vision of cohesion of the individual, family and community in the political, legal, psychosocial And territorial, with a focus on gender, ethnic and sexual orientation.
\end{abstract}

Key words: Gender violence, Human rights, Peacebuilding, Gender focus, Principle of equality, Public actions. 


\section{Introducción}

$\mathrm{Al}$ revisar una buena parte de documentación respecto a Violencia de Género y el proceso de paz con participación de las mujeres, se reafirma en los resultados que las acciones para la creación de cultura de paz han contribuido y promovido el mejoramiento de la convivencia social y ciudadana. Dichas acciones han generado opiniones diversas, masa crítica, nuevas formas de pensar, sentir y vivir, pretendiendo la exigibilidad al disfrute de los derechos humanos desde la perspectiva del ejercicio activo y eficaz de estos, no importando el escenario político, social, religioso e ideológico que se muestre. Lo que importa es lograr asumir el gran reto de reconstruir tejido social con paz, convivencia, democracia desde las nuevas espacialidades, para las poblaciones más vulnerables y la población en general.

Bajo el amplio espectro de la temática, es importante destacar que el principio de igualdad, el reconocimiento a las diversidades, la legitimidad de las acciones positivas para superar la discriminación, la integralidad de los Derechos Humanos Universales, su interrelación e indivisibilidad con los derechos de las mujeres, la protección de los derechos reproductivos y las opciones sexuales, la relevancia de la reforma del Estado y las formas de organización territorial, la paridad en la representación política y el papel estratégico del movimiento organizado de mujeres para lograr la igualdad real entre hombres y mujeres, forman parte de la serie de presentaciones que tuvieron lugar en Santa Cruz en febrero de 2005 (Montaño y Aranda, 2006). Es así como dentro del marco del proyecto Gobernabilidad Democrática e igualdad de género, se expresó que:

Busca fortalecer e integrar las demandas y necesidades de la mujer en los programas nacionales de los Gobiernos y que es ejecutado con el apoyo de la Cuenta para el Desarrollo de las Naciones Unidas, la Unidad Mujer y Desarrollo de la Comisión Económica para América Latina y el Caribe (CEPAL), que en coordinación con la Corte Nacional Electoral de Bolivia, organizó un Seminario Internacional sobre Reformas constitucionales y equidad de género, los días 21, 22 y 23 de febrero en la ciudad de Santa Cruz, Bolivia. (Montaño \& Aranda, 2006, p.22) 
Es así como las acciones realizadas por la sociedad civil, representada por plataformas de mujeres, colectivos, confluencias, redes en sus diferentes expresiones, donde las féminas localizadas en lo largo y ancho del territorio colombiano, han facilitado con su actuación proactiva y política que se evidencie la escasa participación de las mujeres en espacios de poder, así como el desconocimiento social e institucional de los derechos de las mujeres respecto de su cuerpo, y los derechos sexuales y reproductivos asociados a la dignidad, proyecto de vida y libertades fundamentales de las mujeres.

En congruencia con los planteamientos presentados, la participación política de las mujeres en los procesos de negociación en pro de la paz, se constituye en herramienta política y una oportunidad única e impostergable para incidir con contundencia en el anhelado y esperanzador camino de una paz duradera; además de ser un derecho consignado en la Resolución 1325, aprobado por el Consejo de Seguridad adoptado el 31 de octubre de 2000 por la ONU (Ramos, 2010).

Asimismo, dentro de esta participación política de las mujeres en esos procesos de negociación, es básico lo que señala la Ley 1257 de diciembre 4 de 2008 en sus 39 articulados, publicada en el Diario Oficial El Heraldo, "por la cual se dictan normas de sensibilización, prevención y sanción de formas de violencia y discriminación contra las mujeres, se reforman los Códigos Penal, de Procedimiento Penal, la Ley 294 de 1996 y se dictan otras disposiciones”.

A pesar de eso, la Política Pública Nacional de Equidad de Género reconoce el aporte que las mujeres hacen a la producción y reproducción de nuestra sociedad. Las mujeres como sujetos sociales contribuyen al desarrollo del país en todos los ámbitos; sin embargo, persisten diversas formas de discriminación que todavía las afectan y que impiden el ejercicio de sus derechos, así como la ampliación de sus capacidades. Existe en Colombia una brecha considerable entre el reconocimiento de derechos y su ejercicio para la mayoría de mujeres, especialmente para aquellas que enfrentan situaciones de especial vulnerabi- 
lidad o aquellas que evidencian la intersección de múltiples discriminaciones, generándoles una afectación desproporcionada al igual que una relación inequitativa.

Por ello el Gobierno Nacional en la búsqueda de la paz, pone en marcha un conjunto de acciones estratégicas, planes y escenarios para hacer visibles a las mujeres, que permitan avanzar en la superación de la discriminación garantizando el ejercicio de los derechos de las mujeres, generando beneficios para el conjunto de la población colombiana que dinamizan en una sociedad más equitativa, incluyente, próspera, democrática y en paz (Alta consejería Presidencial para le equidad de la mujer, 2012).

Lo anterior explicado, exige reinventar desde las nuevas espacialidades, nuevos territorios con el sueño de un "gran contrato social", enfocado en el construir de manera permanente acuerdos sociales, micro-locales donde el medioambiente tenga dolientes, querientes donde existan servicios públicos de salud, educación, energía, agua, entre otros, no asediado por la corrupción, donde la academia posea cátedras contextualizadas y actualizadas de derechos humanos que tomen en cuenta las diferencias culturales y de los territorios, generando el cambio social también desde el aula.

Otra situación que ha merecido brindar acciones afirmativas es la denuncia permanente a la negligencia o prácticas de corrupción por parte de funcionarios en el trámite de denuncias o investigaciones judiciales y administrativas, como se menciona en el Departamento Nacional de Planeación (DNP, 2014), cuyas acciones permiten tener un marco normativo de gran importancia. Sin embargo, la realidad social ante este escenario es otra, ya que las mujeres en Colombia requieren empoderarse a través de un proceso de capacitación en referencia a la diversidad de normas, programas y fundaciones que le brindan respaldo cuando sus derechos son violentados.

Sobre la base de los Estándares Básicos de Competencia Ciudadana, de acuer- 
do a lo establecido en el portal web del Ministerio de Educación Nacional, las respuestas que se tenían a las preguntas elaboradas desde hace más de diez y veinte años, no han sido cambiadas, por lo que toca reinventar cómo construir democracia, paz y un nuevo orden social donde el respeto, la convivencia, la justicia social y la igualdad de género sean posibles, y cuenten con sabor a Democracia con Justicia Social.

Dentro del ambiente de Democracia con Justicia Social, son importantes las siguientes Acciones Afirmativas, que se enumeran a continuación de acuerdo a los planteamientos realizados por López (2016):

1. Visibilizar el trabajo de mujeres de diferentes plataformas, colectivos, comités, motivando la generación de conocimiento desde cada saber, para que funcionen los mecanismos de protección y garantías constitucionales hacia la búsqueda de una paz duradera con democracia y justicia social.

2. Reconocer las mesas de trabajo de mujeres de diferentes plataformas, colectivas, nacionales e internacionales con equipos y expertos en temas de paz, liderando réplicas y experiencias nacionales e internacionales desde cada saber con enfoque diferencial, etario, étnico, poblacional, de sexo, y género.

3. Mujeres de diferentes plataformas, colectivos, comités realizando cursos, formularios, talleres, diplomados de DESC (derechos económicos, sociales, culturales), diplomado en Democracia, ciudadanía, política pública, participación política, empoderamiento, empleabilidad femenina, construcción de ciudadanía, estrategias de educación en salud sexual y reproductiva, promoción y difusión de las normativas dirigidas a garantizar los derechos de las mujeres, como un ejercicio real en la ciudadanía desde todos los enfoques que garanticen inclusión social.

4. Mesa interinstitucional para erradicar la Violencia contra la Mujer en el departamento de Atlántico: práctica pública que desde la institucionalidad y sociedad civil logra avances significativos en protección, prevención a mujeres víctimas de violencia; con la participación de Organismos Gubernamentales de Protección, Defensoría del Pueblo, Personería, Contraloría, 
Procuraduría; instituciones: Secretaría y oficinas de Mujer, secretarías de educación, salud, deporte, cultura, gestión social; las plataformas, organizaciones de mujeres.

5. Encuentros para tejer memoria, jornadas lúdicas, talleres, eventos científicos y académicos (como herramienta para generar empoderamiento y construcción de ciudadanía, experiencias desde la Universidad Simón Bolívar, programa de Trabajo Social y acciones con defensoría del pueblo, oficina de la mujer distrital y secretaría de la mujer departamental).

6. Mesas de trabajo para revisar, hacer seguimiento al rol de los Organismos No Gubernamentales de Protección-ONG’s y la Cooperación Internacional, tratando de dar garantía para el cumplimiento de los Derechos Humanos en la población de una nación, desde lo territorial.

7. Mesas por la paz; apuestas, escenarios permanentes de reflexión para crear ambientes estables de debate, que den garantía a la implementación de los acuerdos de paz (organizaciones de mujeres, academia, iglesias, plataformas de derechos humanos, institucionalidad).

8. Consejos de Seguridad con mujeres y para mujeres hacia la prevención y protección de la vida de ellas. Espacios que en 4 años se han avanzado en algunas propuestas desde la incidencia y exigencia de las organizaciones de mujeres con aliados desde la institucionalidad; medios de comunicación, actualmente existe un espacio de reflexión y acción con la Secretaría de la Mujer del departamento del Atlántico.

9. Planes de desarrollo y políticas públicas de género en seguimiento para que la apuesta sea implementar programas con presupuestos sensibles al género, y se insista en la consolidación de un sistema de información oficial que unifique criterios, respuestas efectivas a las quejas, investigaciones, condenas y sanciones.

10. Las plataformas de mujeres y otros géneros visibles en la exigibilidad de derechos con acciones públicas: plantones, cirirí, tomas, canelazos, cacerolazos, toma de medios, diplomados, escuelas, charlas, tratando de construir Convivencia y Ciudadanía con buenas prácticas para lograr el ejercicio y disfrute de los Derechos Humanos, derechos fundamentales en la cotidianidad. 
11. Las redes de mujeres, colectivos, confluencias, plataformas construyendo nuevas formas de diálogo, de generación de confianza, revisando el accionar del trabajo para mejorar las prácticas que no favorecen la unidad y aumentar el nivel de cohesión, integración y sinergia para construir un movimiento sólido capaz de trasformar realidades de manera concertada y organizada.

12. Acciones desde la lúdica y animación sociocultural haciendo ejercicios desde el arte, la cultura, la educación como fuente de desarrollo social; experiencia comparsa del Carnaval de Barranquilla.

13. Mujeres en mesas de trabajo revisando la cultura de participación política de las mujeres, mediada por el modelo de relaciones desigual y el modelo patriarcal que influye en los partidos políticos.

14. Aumentar la confianza en la participación política de las mujeres, ya que por el miedo a ser amenazadas o represalias se niegan a participar.

15. Denuncias públicas en instancias judiciales y en medios de comunicación que develan la discriminación a todas las mujeres y a otros géneros, a los jóvenes, la población indígena, campesina, rom, afrodescendiente, personas discapacitadas.

16. Denuncias a medios de comunicación que utilizan estereotipos en contra de las mujeres y el lenguaje sexista.

17. Utilización de redes sociales e instancias judiciales para veeduría a políticos corruptos y prácticas no éticas.

18. Denuncias, caminatas, plantones, toma de redes sociales por los megaproyectos que se ejecutan y afectan el ambiente que cada día está en deterioro, los servicios públicos (agua, luz, gas, telefonía) cada día más asediados por la corrupción.

19. Denuncias a la ausencia de cátedras contextualizadas y actualizadas de derechos humanos por sector educativo que tomen en cuenta las diferencias culturales y de los territorios.

20. Acciones de las plataformas visibilizando la gran problemática de los afrodescendientes, el proceso de reclutamiento forzado de indígenas por parte de la fuerza pública. Incumplimiento en aplicación de la consulta previa a 
grupos étnicos, las condiciones laborales para la población indígena, afrocolombiana, raizal, campesina, población Rom en Colombia. Los refugiados(as) (Venezuela y otros países latinoamericanos).

21. Las acciones públicas que hacen visible la exigencia al derecho a la participación de las víctimas en la construcción de la verdad judicial buscando que se erradique la corrupción e impunidad en el sistema de justicia.

22. Denuncias permanentes, exigiendo cada día mayor formación y competencias de los funcionarios que atienden a las víctimas, especialmente en aplicación de la norma buscando aumentar la credibilidad y confianza en el Estado y la justicia.

\section{Conclusiones}

Transversalizar los enfoques (género, diversidad cultural, diversidad etaria, de discapacidades) es el proceso de valorar las implicaciones para las mujeres y para los hombres (género), para las personas de otras culturas (diversidad cultural) para las personas de diferentes edades (diversidad etaria) y para las personas con diferencias en sus capacidades, de cualquier acción que se planifique, trátese de legislación, políticas o programas en todas las áreas y a todos los niveles (de hogares, comunitario, institucional, nacional o global).

La Constitución de 1991, artículo 13, dice que "el Estado promoverá las condiciones para que la igualdad sean real y efectiva, y adoptará medidas a favor, sea discriminadas o marginadas. En el 2002 la sentencia C371 institucionaliza el término acciones afirmativas (Andrade \& Andrade, 2012).

Dentro de esta participación política de las mujeres en esos procesos de negociación, es básico lo que señalan las normativas referentes a la defensa de los derechos de las mujeres, en especial, la participación política y los nuevos acuerdos de paz, lo que supone reinventar desde las nuevas espacialidades, desde lo micro, local, nacional y en espacios internacionales, las acciones afirmativas en defensa de los derechos humanos, en especial de las mujeres. 


\section{Referencias Bibliográficas}

Alta Consejería Presidencial para la Equidad de la Mujer (2012). Lineamientos de la política pública nacional de equidad de género para las mujeres. Bogotá, Colombia.

Andrade \& Andrade (2012). Acciones Afirmativas (Políticas Educativas Internas de las universidades públicas colombianas para los afro-colombianos). Revista Zona. Publicación semestral 13.

Departamento Nacional de Planeación (DNP) (2014). Denuncia actos de corrupción. Recuperado de: https://www.dnp.gov.co/atencion-al-ciudadano/consultas-quejas-y-reclamos/Paginas/denuncia-actos-de-corrupcion.aspx

Diario Oficial El Abedul. República de Colombia. Ley 1257 de diciembre 4 de 2008. Congreso de Colombia. Recuperado de: http://www.sdmujer.gov. co/images/pdf/ley1257.pdf

Heller, H. (1985). “Las ideas socialistas” en Escritos Políticos. (Selección y prólogo de A. López Pina), Alianza, Madrid, 1985, p.322. Vid., también, E. Carmona Cuenca, "El principio de igualdad material en la jurisprudencia del Tribunal Constitucional", Revista de Estudios Políticos, 84, 1994, p.271.

López, E.D. (2016). Acciones Afirmativas en construcción de paz para las mujeres. Congreso mujer y paz Universidad del Norte, Secretaría de la mujer del atlántico, Noviembre 2016. Fundación Teknos.

Ministerio de Educación Nacional (MEN). Lo que necesitamos hacer y saber hacer. Recuperado de: http://www.mineducacion.gov.co/1621/articles-75768_archivo_pdf.pdf

Montaño \& Aranda (2006). Reformas constitucionales y equidad de género. Informe final Seminario Internacional. Santa Cruz de la Sierra, 21, 22 y 23 de febrero. CEPAL. Unidad, Mujer y Desarrollo. Serie 47. Reformas Constitucionales y Equidad de Género. Informe Final. 359p. Recuperado de: http://www.cepal.org/publicaciones/xml/9/25599/lcl2489e.pdf 
Mosquera Rosero-Labbé, León Díaz, R.E. (Ed. y coautoras) (2009). Acciones Afirmativas y ciudadanía diferenciada étnico-racial negra, afrocolombiana, palenquera y raizal. Entre Bicentenarios de las Independencias y Constitución de 1991.

Ramos, M. (2010). El papel de las mujeres en la resolución de conflictos y en la reconstrucción de la paz. Federación de Planificación Familiar Estatal. Recuperado de: http://resolucion1325.blogspot.com.co/ 